\title{
Technology Maturation
}

\section{Compact Accelerator Platform Technology}

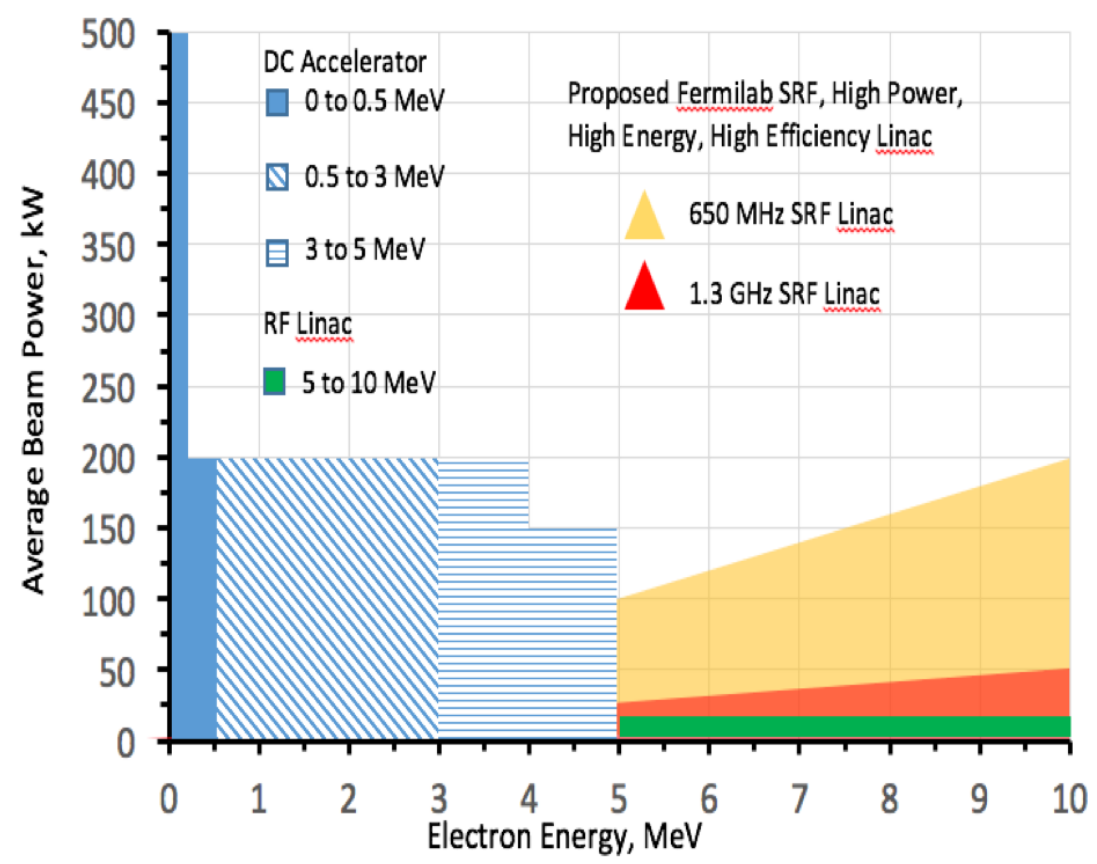

- Currently we are integrating multiple new technologies to create a compact, portable, high power, high reliability electron beam platform accelerator.

- We are concurrently developing applications for this compact accelerator.

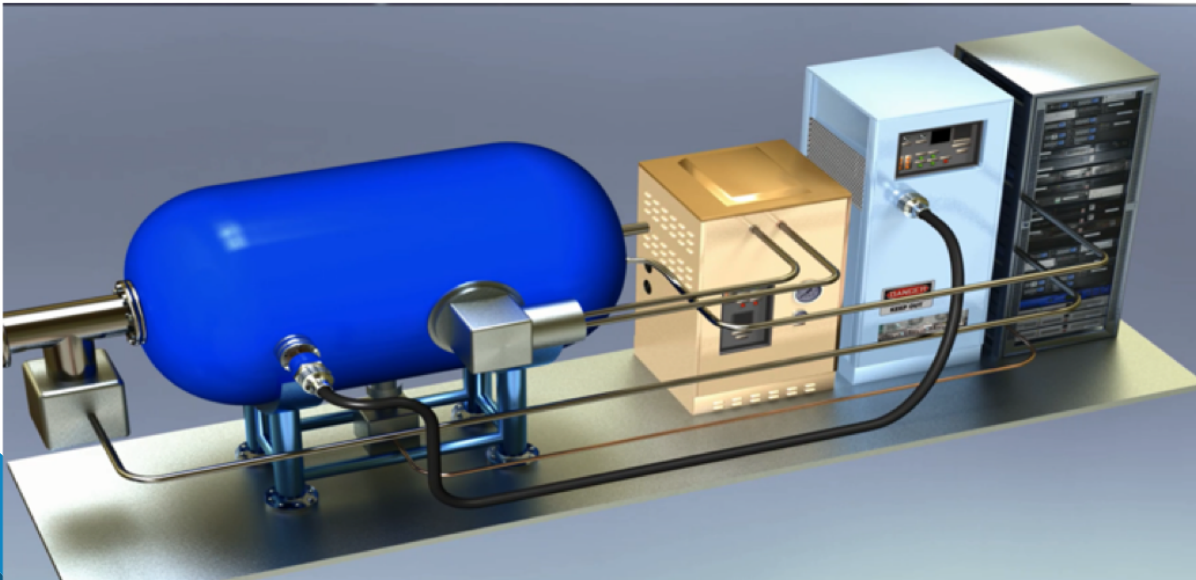

This manuscript has been authored by Fermi Research Alliance, LLC under Contract No. DE-AC02-07CH1 1359 with the U.S. Department of Energy, Office of Science, Office of High Energy Physics 


\section{Application Areas}

- Water/Biosolids

- Cargo Scanning (DNDO)

- Modification of Materials (like pavement - ERDC)

- Medical Sterilization(NNSA)

- Driving various industrial chemistries

- GTL of flare gas

- Rubber

- Environmental remediation, Advanced Mnfg, food treatment, surface hardening, digital electronics, mining
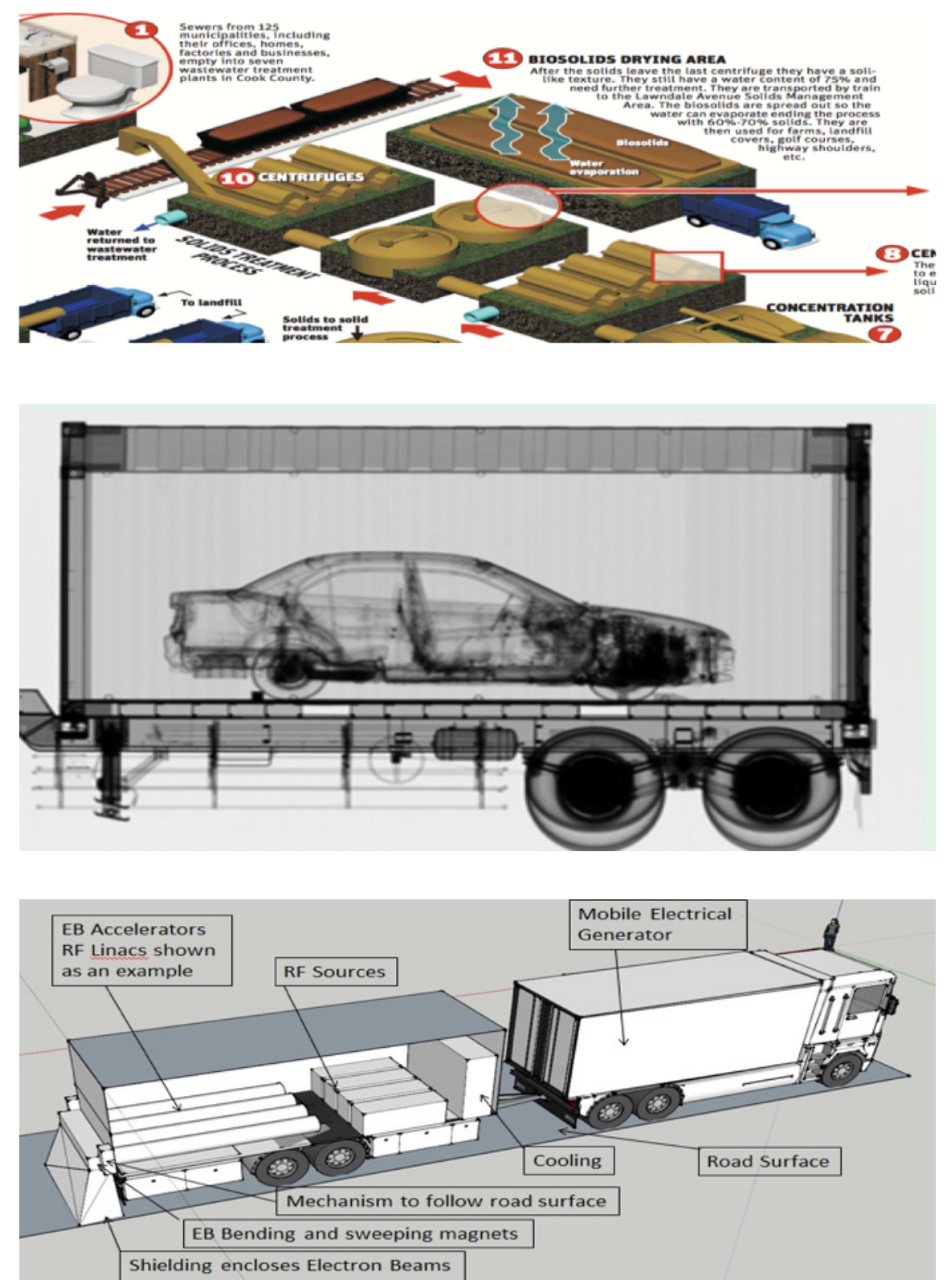


\section{Compact Accelerator for Pavement}

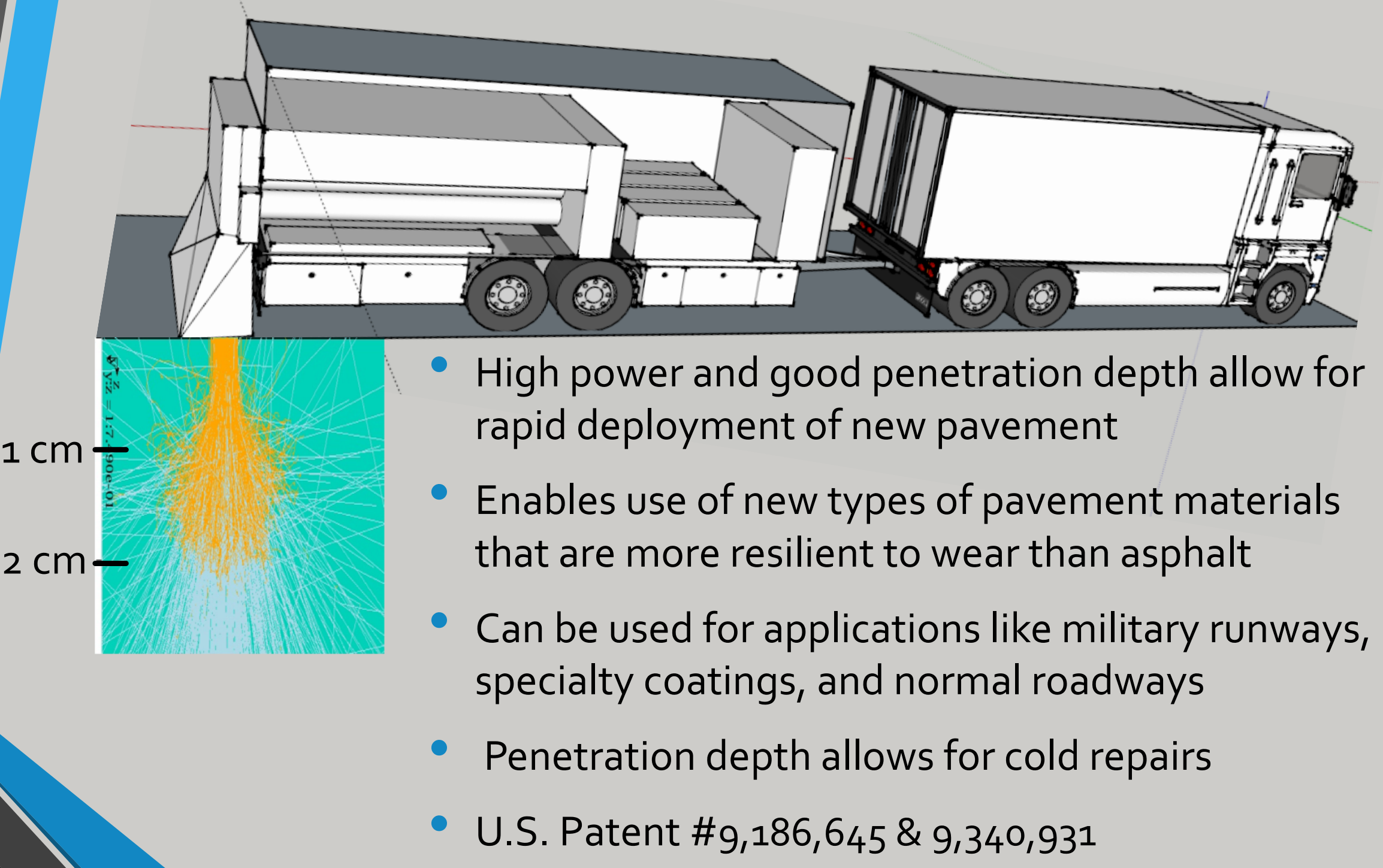




\section{Compact Accelerator for Environmental Remediation}

- In several pilot programs electron accelerators have be proven to be effective at destroying toxic organic contaminates in water and soil

- Typically large volumes of material are removed from contaminated areas creating a concern of secondary contamination

- Key to deployment at large scale is development of high power (100's of $\mathrm{KW}$ to MW class) industrial electron accelerators that are cost effective and reliable

- Compact Accelerator could enable new in-situ environmental remediation or decontamination processes

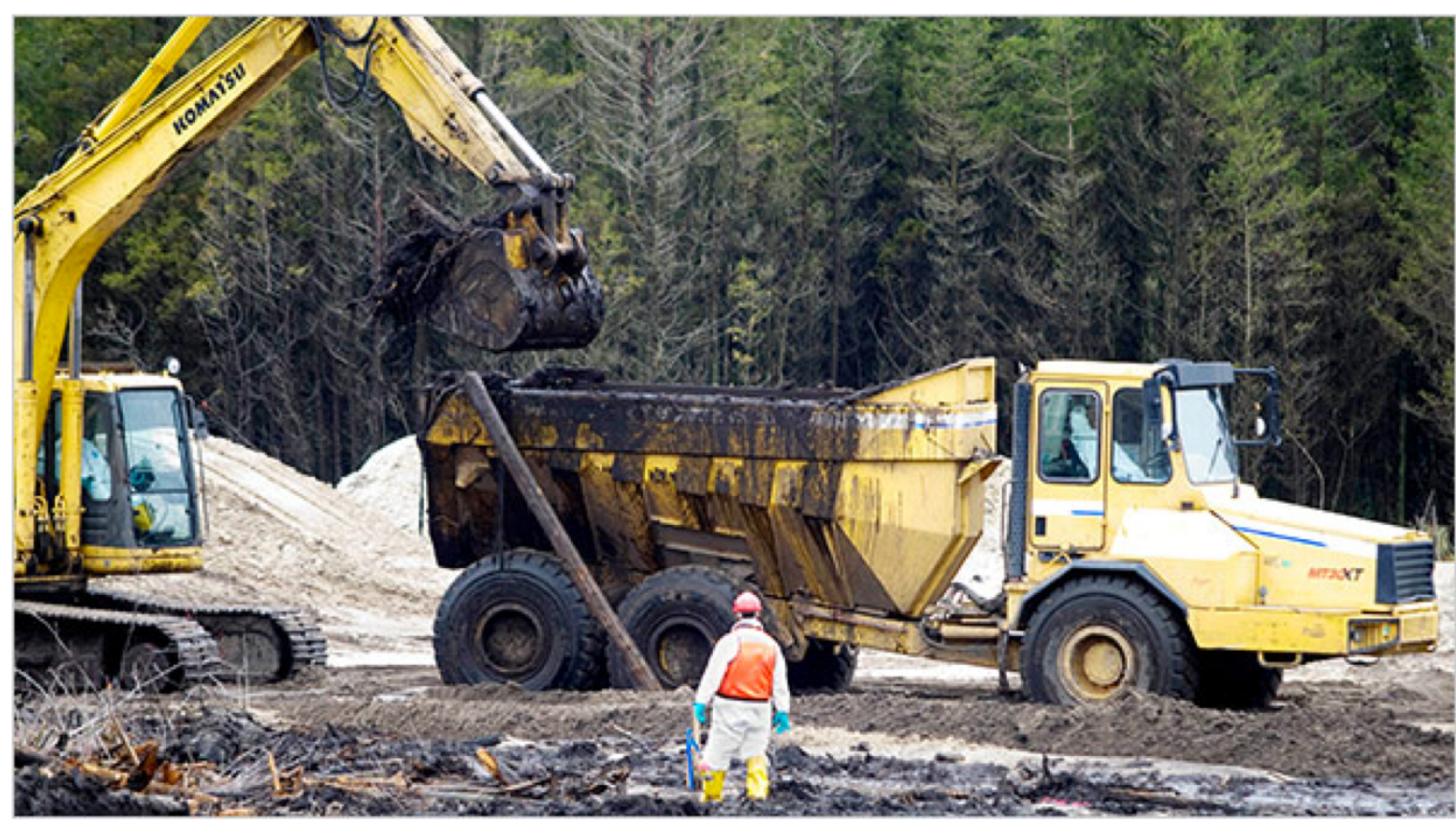




\section{Compact Accelerator for Crops}

E-Beam treatment can improve shelf life, destroy disease causing bacteria and be used for pest control

- A portable high power accelerator has the potential for saving crops in quarantined areas

- Potential for large cost saving as quarantined crops are often destroyed
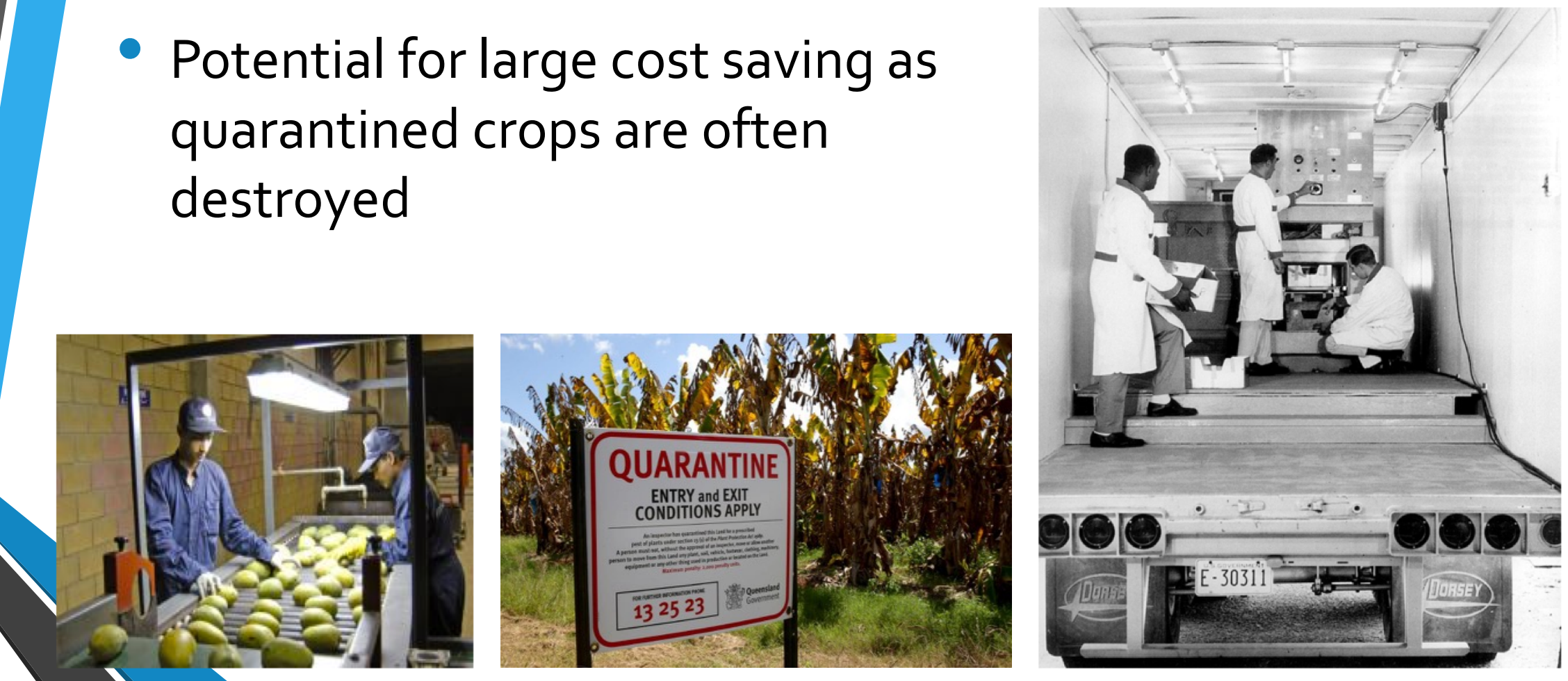


\section{Compact Accelerator for Driving Chemistry}

- In the U.S. Industry consumes $\sim 32 \%$ of end use sector

- $27 \%$ of that is used in the Chemical Sector (www.eia.gov)

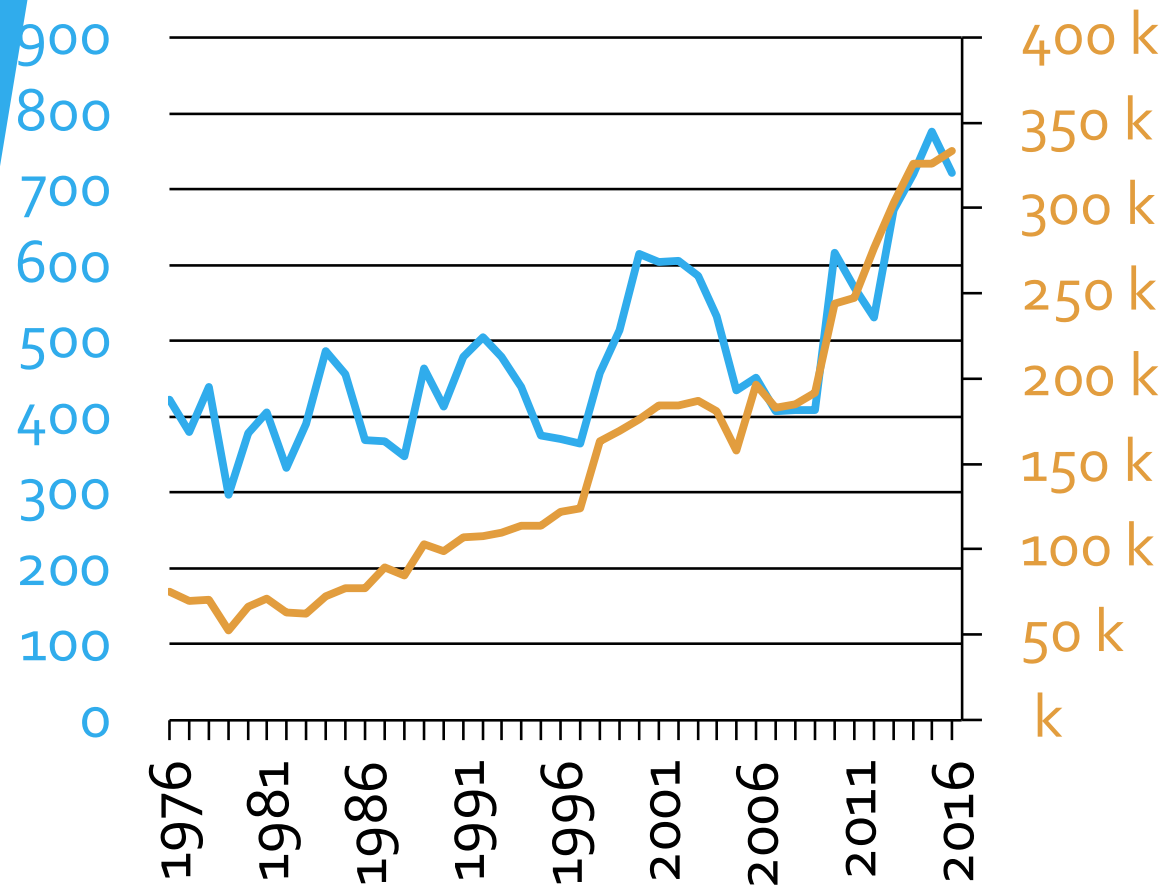

- Demonstrated industrial effort to develop catalyst to increase efficiency

- Electron Beam Driven Chemistry largely unexplored

- More efficient that direct heating

- Rubber Industry

- Can remove need for some toxic initiators, cross linkers

Total \# US Original Catalyst Patents

Total \# US Original Patents

patft.uspto.gov 


\section{US E-beam Treatment of Wastewater}

- *CN Kurucz et al., "The Miami electron beam research facility: a large scale waste water treatment application", Radiat. Phys. Chem. Vol. 45, pp299-308 (1995)

- High Voltage Environmental Applications, Inc., Electron Beam Technology Innovative Technology Evaluation Report - August 1997 - EPA, NRMRL

- Workshop on Energy and Environmental Applications of Accelerators at ANL in June of 2015 developed language that was used in 2016 Accelerator Stewardship program.

- Design 1 MW accelerator for waste water treatment 


\section{Why Use E-Beam for Water Treatment?}

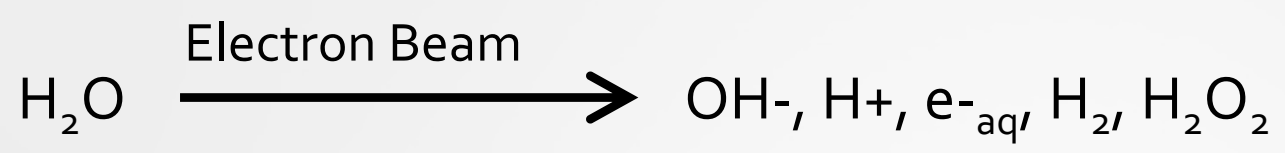

- Primarily works by generating oxidizing and reducing radicals from the water

- But can directly decompose contaminants as well

- Removal of toxic chemicals not removed in conventional domestic water treatment

- Pharmaceuticals

- Agricultural run off

- PCBs

- Fuel additives (MTBE)

- Explosives

- No toxic residuals (no secondary waste generation)

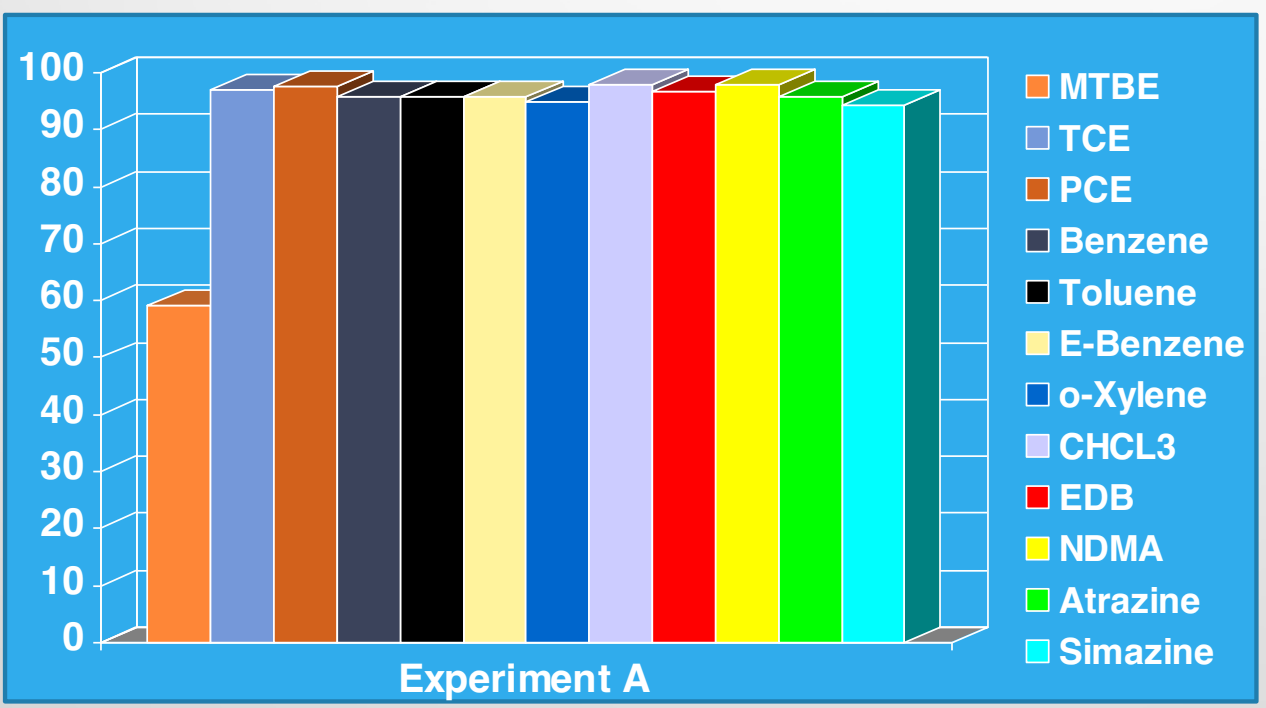

*William J. Cooper, Dept. of Civil and Env. Engineering, UC, Irvine 


\section{Demonstration: Municipal Waste Water}
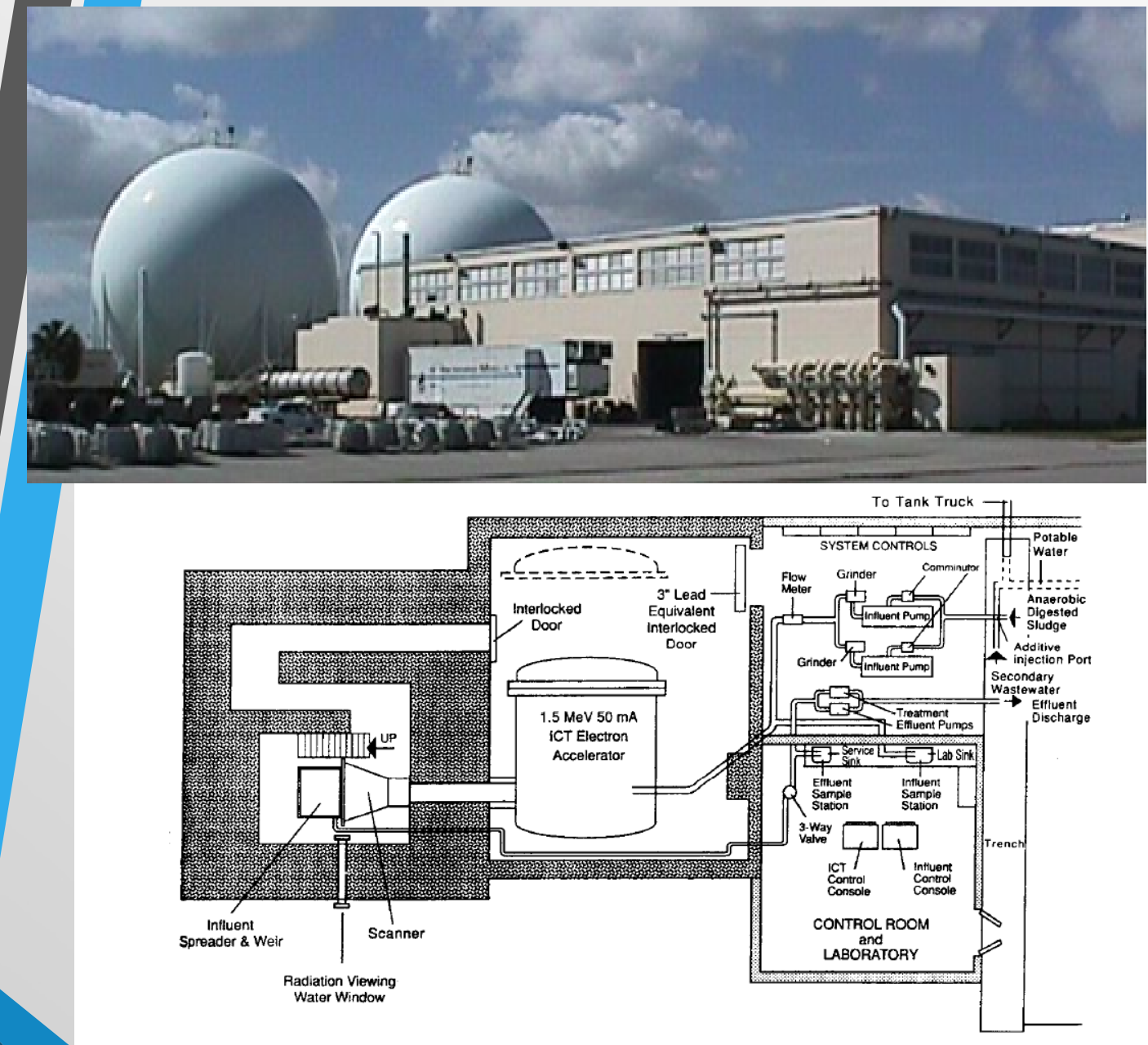

- Miami, Florida treatment facility

- 150 GPM

- Effective in disinfecting and removing organic waste from municipal waste water

- Treatment cost estimated at 1.5-2 cents/gal in 1995

*CN Kurucz et al., "The Miami electron beam research facility: a large scale waste water treatment application", Radiat. Phys. Chem. Vol. 45, pp299-308 (1995) 


\section{Textile Wastewater Treatment}

- Treatment of $1000 \mathrm{~m}^{3} / \mathrm{day}$

Influent

$80,000 \mathrm{~m}^{3} /$ day $\quad 1,000 \mathrm{~m}^{3} /$ day

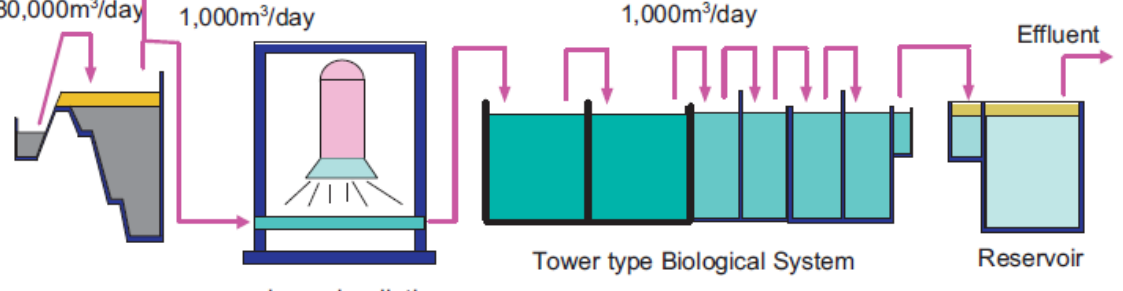

e-beam irradiation
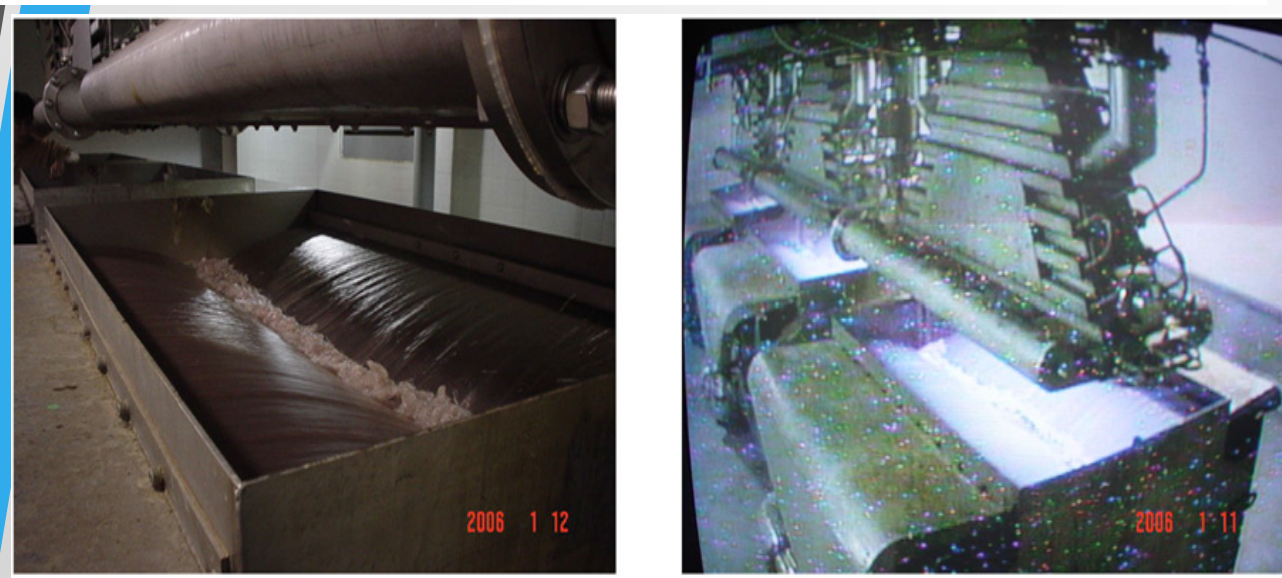

Interaction area of water and beam (beam on to the right) (180 gpm) of water from textile dyeing process

- Showed significant decrease in TOC, $\mathrm{COD}_{\mathrm{Cr}}$ and $\mathrm{BOD}_{5}$ (30$40 \%$ increased removal eff.)

- Based of earlier success 10,000 $\mathrm{m}^{3} /$ day plant constructed for $\$ 4 M U S$ in 2005

- Operational cost measured to be 0.11 cents/gal. 


\section{Municipal Water Treatment via Compact Accelerator}

- Currently partnered with Metropolitan Water Reclamation District of Chicago

- Stickney plant, largest in the world (1.2 Billion gal/day)

- Incoming water is a fuel source not just waste

- Goal of net zero energy operation

- Desire to recover nitrates.

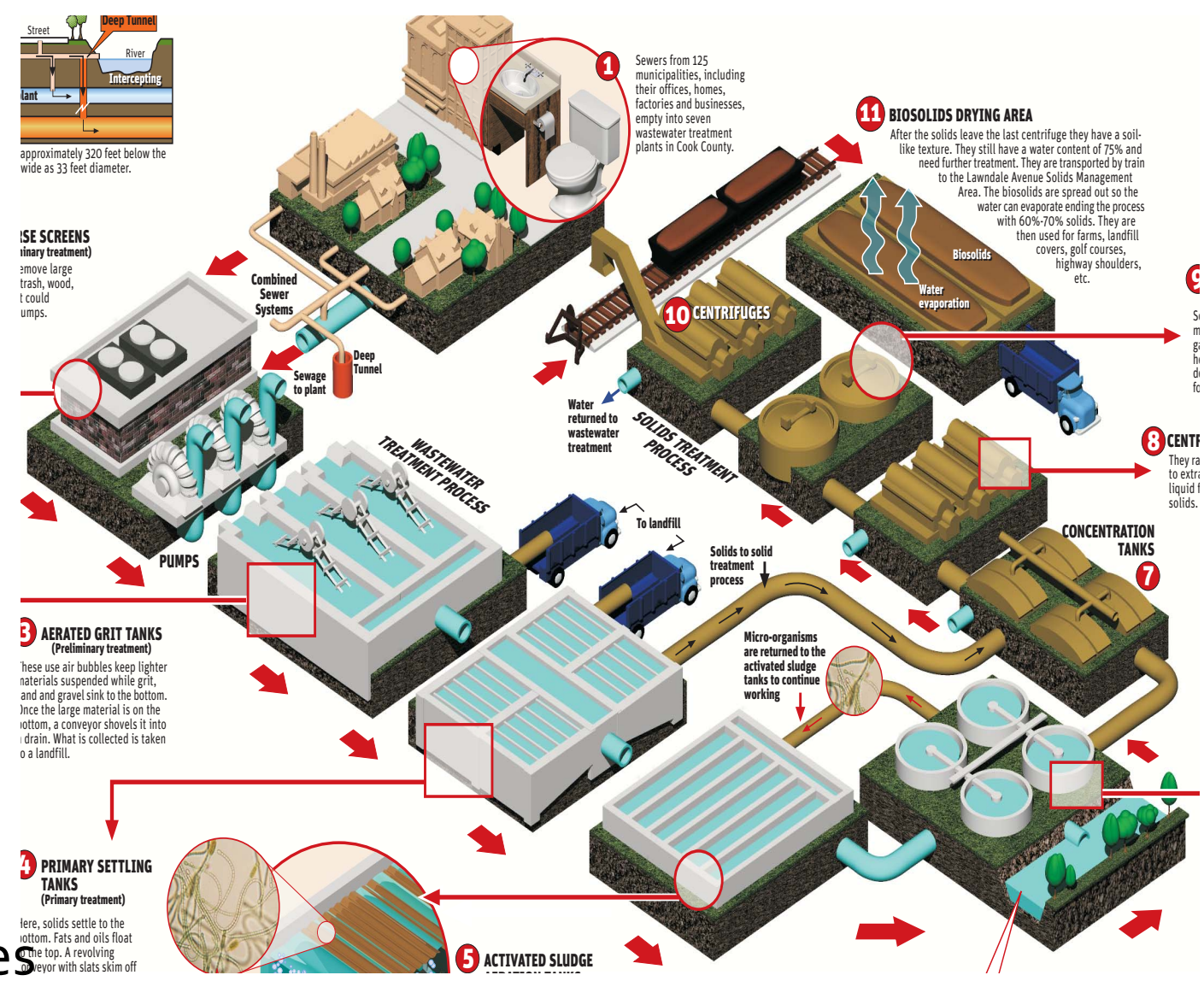
and phosphates

- Biosolids can be sold as fertilizer

- Treat 2MGD with $1 \mathrm{MW}$ of total power, treat at Thickened WAS stage ( $5 \%$ solids before anaerobic digester) 
We are integrating multiple new technologies to create a compact,

portable, high-power electron beam platform accelerator.

Electron-beam application development must be done because of the

new application areas that the Compact Accelerator enables

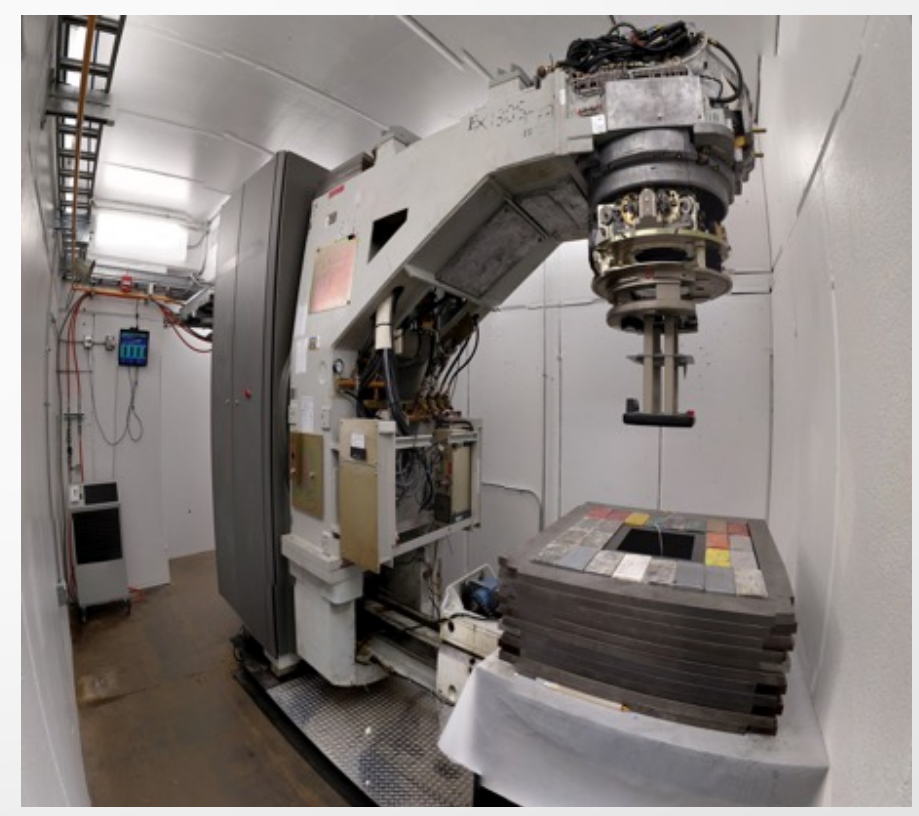

- A2D2 allows for precise control of development work so that the beam, beam sample interaction and analytical data taken can be changed as needed 


\section{$\mathrm{A}_{2} \mathrm{D}_{2}$ Beam Info}

(Fully Open)

\begin{tabular}{|l|c|c|}
\hline $\begin{array}{l}\text { Positi } \\
\text { on }\end{array}$ & $\begin{array}{l}\text { Beam } \\
\text { Diameter, } \\
\mathrm{cm}\end{array}$ & $\begin{array}{l}\text { Distance } \\
\text { from } \\
\text { Collimator, } \\
\mathrm{cm}\end{array}$ \\
\hline 1 & 4.8 & 63 \\
\hline 2 & 5.7 & 75 \\
\hline 3 & 7.1 & 93 \\
\hline 4 & 10.3 & 135 \\
\hline 5 & 12.6 & 165 \\
\hline
\end{tabular}

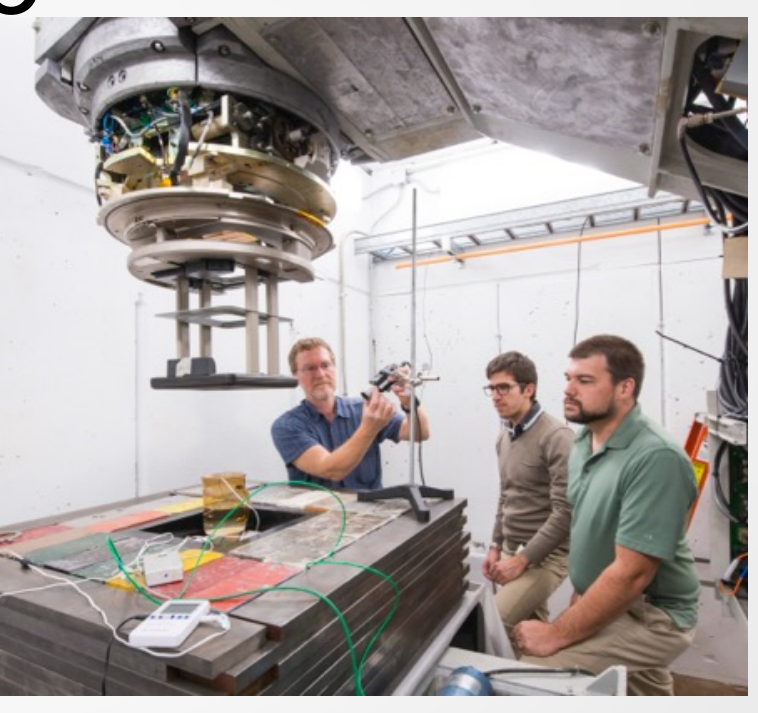

\begin{tabular}{|l|c|c|}
\hline Setting & $\begin{array}{l}\text { Power, } \\
\mathrm{kW}\end{array}$ & $\begin{array}{l}\text { Dose } \\
\text { Rate, } \\
\mathrm{kG} / \mathrm{kg}-\mathrm{s}\end{array}$ \\
\hline 1 & 0.22 & 0.22 \\
\hline 2 & 0.43 & 0.43 \\
\hline 3 & 0.65 & 0.65 \\
\hline 4 & 0.87 & 0.87 \\
\hline 5 & 1.08 & 1.08 \\
\hline 6 & 1.3 & 1.3 \\
\hline
\end{tabular}

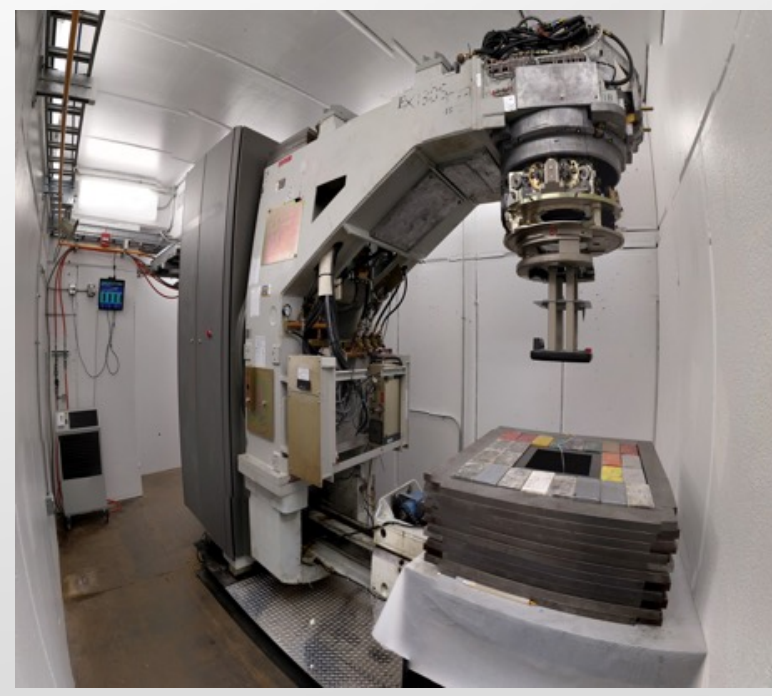




\section{Dose Distribution $9 \mathrm{MeV}$ Electron in Water, Rock (Density 3.75)}

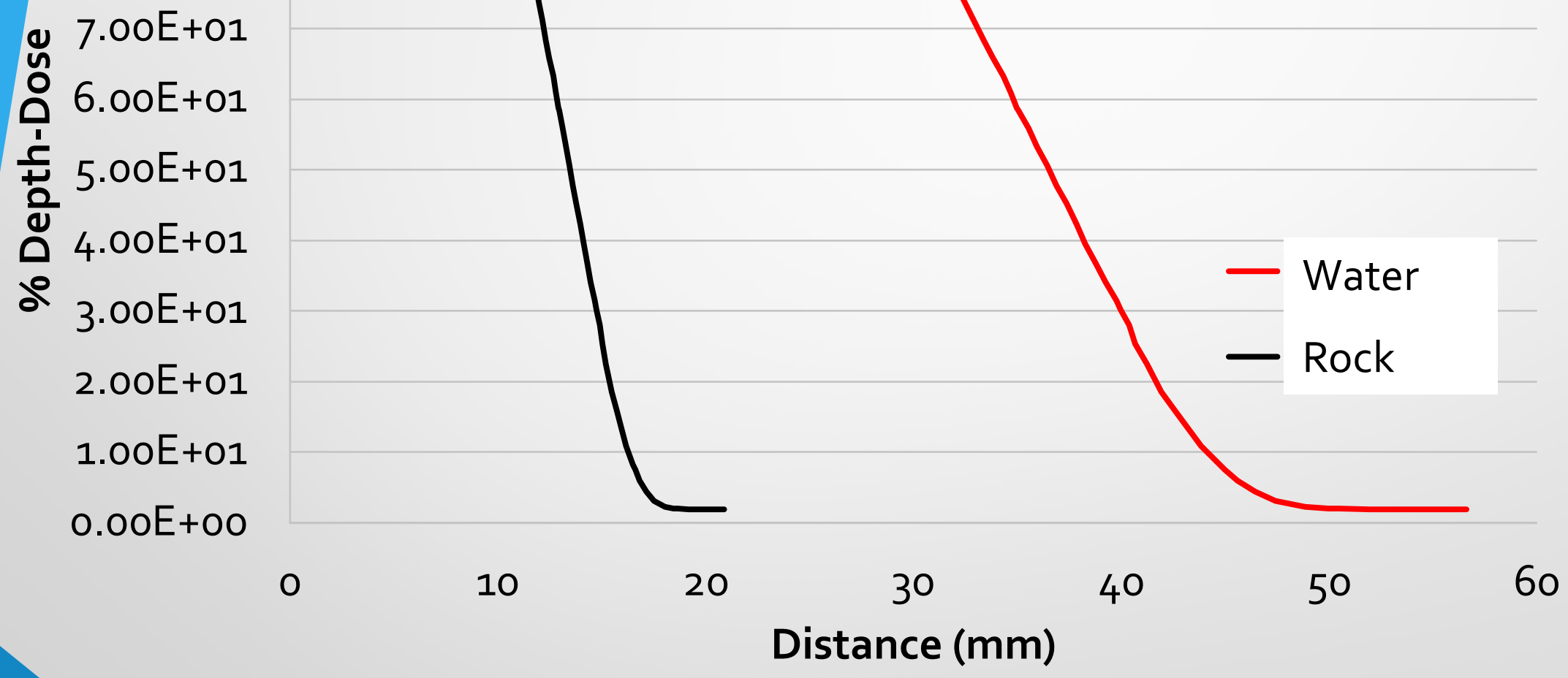


Title:

Workshop on Application of Electron Beam (EB) Technology on Wastewater and Biosolids Treatment

\section{Purpose:}

-Promote use of e-beam technology for wastewater treatment

- Inform water treatment professionals about e-beam technology and opportunities

-Provide feedback to NSF that opens future funding opportunities

\section{Format:}

This two-day workshop will include expert speakers on the current state of wastewater treatment, a summary of the science of using e-beam technology for treatment of waste, the current state of e-beam accelerator technology, a tour of Fermilab National

Accelerator Lab, panel discussions with water treatment experts, breakout discussions and a summary close-out session.

Post conference a report will be issued with findings and recommendations.

\section{Where:}

Illinois Accelerator Research Center, Fermi National Accelerator Lab

\section{When:}

May 10-11, 2018 (Thursday-Half Day Friday)

Who: By invitation only: Water treatment professionals, e-beam researchers, industrial accelerator experts, industry and utilities partners, regulatory personnel, NSF and Federal and State government officials 